\title{
Activation of a Neospora caninum EGFR-Like Kinase Facilitates Intracellular Parasite Proliferation
}

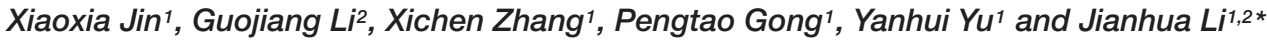 \\ ${ }^{1}$ Key Laboratory of Zoonosis, Ministry of Education, College of Veterinary Medicine, Jilin University, Changchun, China, ${ }^{2}$ Jilin \\ Agricultural Science and Technology University, Jilin, China
}

OPEN ACCESS

Edited by:

Bang Shen,

Huazhong Agricultural University,

China

Reviewed by:

Alejandra Victoria Capozzo, Consejo Nacional de Investigaciones Cientificas y Técnicas (CONICET),

Argentina

Jing Liu,

China Agricultural University, China

${ }^{*}$ Correspondence:

Jianhua $L$

jianhuali7207@163.com

Specialty section:

This article was submitted to Infectious Diseases,

a section of the journal

Frontiers in Microbiology

Received: 16 May 2017

Accepted: 25 September 2017

Published: 12 October 2017

Citation:

Jin X, Li G, Zhang X, Gong P, Yu Y and $L i J$ (2017) Activation of a Neospora caninum EGFR-Like Kinase Facilitates Intracellular Parasite Proliferation. Front. Microbiol. 8:1980. doi: 10.3389/fmicb.2017.01980
The Apicomplexan parasite Neospora caninum, an obligate intracellular protozoan, causes serious diseases in a number of mammalian species, especially in cattle. Infection with $N$. caninum is associated with abortions in both dairy and beef cattle worldwide which have a major economic impact on the cattle industry. However, the mechanism by which $N$. caninum proliferates within host cells is poorly understood. Epidermal growth factor receptor (EGFR) is a protein kinase ubiquitously expressed, present on cell surfaces in numerous species, which has been confirmed to be essential in signal transduction involved in cell growth, proliferation, survival, and many other intracellular processes. However, the presence of EGFR in N. caninum and its role in $N$. caninum proliferation remain unclear. In the present study, we identified a putative EGFR-like kinase in N. caninum, which could be activated in tachyzoites by infection or treatment with $\mathrm{rNcMIC3}$ [containing four epidermal growth factor (EGF) domains] or human EGF. Blockade of EGFR-like in tachyzoites by AG1478 significantly reduced parasite proliferation in host cells. Our data suggested that the activation of tachyzoite EGFR-like might facilitate the intracellular proliferation of $N$. caninum.

Keywords: $N$. caninum, EGFR, AG1478, PKC activity, parasite proliferation

\section{INTRODUCTION}

Neospora caninum, classified in the phylum Apicomplexa (Dubey et al., 2002), infects a variety of mammalian species with a worldwide distribution which results in severe protozoosis-Neosporosis (Dubey, 2003). Infection with N. caninum mainly leads to abortions and stillbirths in pregnant herds and neuromuscular disorders in newborns which cause huge economic losses in the animal husbandry, especially in the cattle production. N. caninum is regarded as the main cause of abortions in dairy cattle throughout the world (Reichel and Ellis, 2008; Dubey and Schares, 2011). Like most of Apicomplexan protozoa, N. caninum is an obligate intracellular parasite. The process of host cells infection by N. caninum includes adhesion, invasion, parasitophorous vacuole formation, and polypide growth. After invasion, replication of $N$. caninum in host cells leads to cell lysis, which results in the release of parasites to invade neighboring cells to repeat the life cycle and establish infection (Innes et al., 2005; Dubey et al., 2007). However, the mechanism by which $N$. caninum proliferates within host cells is not fully elucidated.

The epidermal growth factor receptor (EGFR) is a transmembrane receptor with intrinsic tyrosine kinase (TK) activity belonging to the HER/ErbB protein family, which including HER1 (erbB1, EGFR), HER2 (erbB2, NEU), HER3 (erbB3), and HER4 (erbB4). EGFR, widely 
distributed on the cell membrane among many mammalian species, is a major signal transduction molecule involved in various cellular activities. EGFR signaling pathway plays crucial roles in the regulation of many physiological and pathological processes, such as cell growth, differentiation, migration, apoptosis, and proliferation. EGFR is activated by ligand binding, including epidermal growth factor (EGF) and transforming growth factor alpha. Ligand binding induces receptor homodimerization or heterodimerization with other ErbB/HER members which in turn causes autophosphorylation of EGFR tyrosine residues, resulting in the activation of downstream signal transduction through MAPK, PI3K/Akt, and SAPK pathways (Yang et al., 2017). It has been reported that host EGF binds to EGFR on Trypanosoma cruzi amastigotes to induce signal transduction events and cell proliferation (Ghansah et al., 2002). Inhibition of EGFR TKs blocked the development of Toxoplasma gondii, Sarcocystis neurona, Cryptosporidium parvum, and N. caninum (Gargala et al., 2005; Yang et al., 2014). However, so far EGFR homologs or EGFR-like mediated signal transduction in Apicomplexan parasites have not been reported.

The aim of the present study is to investigate whether EGFR homologs exist in $N$. caninum and its potential function on parasite proliferation in host cells. We found that $N$. caninum possessed a putative EGFR-like protein in tachyzoites which could be activated by $N$. caninum infection or by recombinant NcMIC3 and human EGF (hEGF). The activation of the putative EGFR-like protein could be inhibited by EGFR-specific inhibitorAG1478. Tachyzoite EGFR-like presented rNcMIC3- and hEGFdependent protein kinase $\mathrm{C}$ (PKC) activities which could be inhibited by AG1478. In addition, inhibition of tachyzoites EGFR-TK by AG1478 resulted in decreased parasite proliferation within host cells.

\section{MATERIALS AND METHODS}

\section{Reagents and Antibodies}

Specific EGFR and phospho-EGFR (Tyr1068) rabbit monoclonal antibodies $(\mathrm{mAb})$ were from Cell Signaling Technology, Inc. (Beverly, MA, United States). AG1478 were from Selleck Chemical., Co. (Houston, TX, United States). Beta-actin mouse $\mathrm{mAb}$ was from Proteintech (West Grove, PA, United States). Cy3- or FITC-conjugated goat anti-rabbit or anti-mouse IgG, peroxidase-conjugated goat anti-rabbit and goat anti-mouse IgG were all from Proteintech. Recombinant hEGF was from Sigma Chemical., Co. (St. Louis, MO, United States). Prokaryotic recombinant protein NcMIC3 (rNcMIC3) and mouse antiserum specific for NcSAG1 was produced in our Laboratory. Full-length gene of $N$. caninum MIC3 was subcloned into the pET-28a $(+)$ vector (TaKaRa, Japan) containing the His-tag, and the recombination pET-28a-NcMIC3 contains four EGF sequence repeats.

\section{Cell Culture}

HEK-293 cells (ATCCCRL-1573) and Vero cells (ATCCCCL81 ) were cultured in DMEM supplemented with $10 \%$ heatinactivated fetal bovine serum (FBS) and antibiotic-antimycotic reagents (all from Gibco BRL, Rockville, MD, United States). One day before treatment, the culture medium was changed to DMEM with $2 \%$ FBS.

\section{Neospora caninum Culture and Purification}

Tachyzoites of N. caninum-1 strain (ATCC 50843) were restored at our laboratory. Vero cells were infected with tachyzoites of $\mathrm{Nc}-1$ and cultured at $37^{\circ} \mathrm{C}$ and $5 \% \mathrm{CO}_{2}$ for $3-5$ days in DMEM/F12 supplemented with $2 \%$ heat-inactivated FBS and antibiotic-antimycotic reagents. After spontaneous host cell rupture, parasites and cell debris were washed in cold DMEM/F12 without FBS and harvested by centrifugation at $850 \times g$ at $4^{\circ} \mathrm{C}$ for $10 \mathrm{~min}$. After centrifugation, the pellet was resuspended in cold DMEM/F12 and passed through a 26-gauge needle (Millipore, Billerica, MA, United States) to further break the cells. The obtained mixture was slowly added onto $40 \%$ percoll solution (GE Healthcare, United States) in DMEM/F12 without FBS and separated by centrifugation at $850 \times g$ in a horizontal centrifuge for $30 \mathrm{~min}$. The fraction containing tachyzoites at the bottom of the tube was collected, resuspended in DMEM/F12 without FBS and centrifuged at $850 \times g$ at $4^{\circ} \mathrm{C}$ for $10 \mathrm{~min}$. The final pellet was purified tachyzoites.

\section{Immunofluorescence}

HEK-293 cells were cultured in 24-well plates containing glass slides and serum-starved overnight. Serum-starved Nc-1 tachyzoites were inoculated into the cells or not at a MOI of 10 for $10 \mathrm{~min}$. For parasite immunofluorescence, purified Nc1 tachyzoites were fixed on coverslips coated with polylysine. Coverslips were rinsed in $1 \times$ PBS with $0.05 \%$ Tween-20. Monolayers were fixed with $4 \%$ paraformaldehyde for $15 \mathrm{~min}$, washed three times in PBST and permeabilized in cold $0.25 \%$ Triton X-100 (Life Technologies Corporation, CA, United States) for $10 \mathrm{~min}$. After PBST washing, coverslips were blocked in $5 \% \mathrm{w} / \mathrm{v}$ bovine serum albumin (BSA) for $1 \mathrm{~h}$ at $37^{\circ} \mathrm{C}$. Slides were incubated in the mAb against phospho-tyrosine 1068 EGFR and EGFR $(1 / 1,000)$ or antiserum against NcSAG1 $(1 / 100)$ in PBST containing $3 \% \mathrm{BSA}$ for $1 \mathrm{~h}$ at $37^{\circ} \mathrm{C}$. After washing three times in PBST, slides were incubated with the corresponding secondary antibody conjugated to Cy3 or FITC (1/500) in PBST containing 3\% BSA for $45 \mathrm{~min}$ in the dark. Slides were washed three times in PBST and counter stained with DAPI (1/1,000; GeneCopoeia, United States) for $5 \mathrm{~min}$. After washing, monolayers were then observed using a FV1000 confocal microscopy (Olympus Co., Japan). Specificity of staining was determined by incubating monolayers with secondary antibody only.

\section{Immunoblotting}

Nc-1 tachyzoites were prepared as above. For treatment with EGFs, $2 \times 10^{6}$ tachyzoites were serum-starved overnight and subjected to treatments with $25-400 \mathrm{ng} / \mathrm{ml}$ hEGF or vehicles for $10 \mathrm{~min}$, and with 0 or $100 \mathrm{ng} / \mathrm{ml} \mathrm{rNcMIC3}$ for 5$120 \mathrm{~min}$, respectively. Some sets of tachyzoites $\left(2 \times 10^{6}\right)$ were incubated with $100 \mathrm{ng} / \mathrm{ml} \mathrm{rNcMIC3}$ or $50 \mathrm{ng} / \mathrm{ml} \mathrm{hEGF}$ for 
$0,10,30$, and $60 \mathrm{~min}$ in the presence of AG1478 $(20 \mu \mathrm{M})$ or DMSO. Before and after treatments, parasite pellets were collected, rinsed with cold PBS for three times, and gently sonicated on ice for $15 \mathrm{~s}$ (amplitude 30, $5 \mathrm{~s}$ for $10 \mathrm{~s}$; Sonics and Materials Inc., United States) in RIPA lysis buffer supplemented with protease and phosphatase inhibitors and PMSF (all from Sangon Biotech Co., Shanghai, China) and then lysed on ice. After mixing with $5 \times$ loading buffer, protein extracts were boiled for $5 \mathrm{~min}$ and centrifuged at $10,000 \times g$ for $5 \mathrm{~min}$ at $4^{\circ} \mathrm{C}$. The supernatants were then subjected to electrophoresis on 10\% SDS-PAGE gels (Bio-Rad Laboratories, Inc., United States) in the same amount and transferred to PVDF membrane (Pall Life Sciences, United States) by electroblotting (Bio-Rad). Membranes were blocked for $1 \mathrm{~h}$ in $5 \%(\mathrm{w} / \mathrm{v})$ skim milk in TBST. The expression of $N$. caninum EGFR was detected using antibody to total EGFR $(170 \mathrm{kDa}, 1 / 1,000)$ or phospho-tyrosine $1068 \mathrm{EGFR}(170 \mathrm{kDa}$, $1 / 1,000)$ in TBST overnight at $4^{\circ} \mathrm{C}$, followed by four times washing and incubation with horseradish peroxidase-conjugated affinipure goat anti-rabbit IgG $(1 / 2,500)$ in TBST for $1 \mathrm{~h}$ at room temperature. Protein bands were visualized by using an enhanced chemiluminescence kit (Proteintech Group Inc., United States) and detected using ChemiScope series 5300 (Clinx Science Instruments Co., Ltd., Shanghai, China) according to the manufacturer's instructions. Beta-actin and NcSAG1 was used as the loading control. Intensities of phospho-EGFR were calculated using Image $(\mathrm{NIH})$ and normalized against total EGFR.

\section{PKC Activity Assay}

To determine whether rNcMIC3 or hEGF could induce PKC activity in tachyzoites, a non-radioactive PKC assay kit (Calbiochem, La Jolla, CA, United States) was used. Serum-starved tachyzoites were prepared and subjected to different treatments. One set of tachyzoites $\left(1 \times 10^{7}\right)$ were incubated with rNcMIC3 at concentrations of $0.01-1 \mu \mathrm{g} / \mathrm{ml}$ or with vehicles at $37^{\circ} \mathrm{C}$ for $10 \mathrm{~min}$. One set of tachyzoites $\left(1 \times 10^{7}\right)$ were incubated with 0 or $0.05 \mu \mathrm{g} / \mathrm{ml} \mathrm{hEGF}$ for $10-$ $60 \mathrm{~min}$. To test for activity inhibition, tachyzoites $\left(1 \times 10^{7}\right)$ were incubated with or without the EGFR inhibitor AG1478 $(20 \mu \mathrm{M})$ for $2 \mathrm{~h}$, and then stimulated with $0.1 \mu \mathrm{g} / \mathrm{ml}$ rNcMIC3 or $0.05 \mu \mathrm{g} / \mathrm{ml} \mathrm{hEGF}$ for $10 \mathrm{~min}$. After treatments, tachyzoites pellets were collected, rinsed with HEPES buffer, and lysates were obtained as described above. The lysates were centrifuged at $10,000 \times g$ for $15 \mathrm{~min}$ at $4^{\circ} \mathrm{C}$ and supernatants were used for protein-kinase activity analysis. PKC activity was measured with ELISA according to the manufacturer's instructions. Samples were applied in triplicates in 96-well plates and read at $450 \mathrm{~nm}$ on a Powerwave 200 spectrophotometer (Bio-Tek, Winooski, VT, United States). Relative PKC activity was calculated by dividing PKC activity induced by EGF by the PKC activity of its respective mock-treated control.

\section{Proliferation of $\boldsymbol{N}$. caninum}

HEK-293 cells were cultured in 24-well plates containing glass coverslips prior to inoculation with freshly purified
Nc-1 tachyzoites at a MOI of 10 in the presence of AG1478 or DMSO with the concentration of $20 \mu \mathrm{M}$. For pretreatment on parasites only, tachyzoites were pretreated with DMSO or AG1478 (20 $\mu \mathrm{M})$, then inoculated to HEK293 cells after rinse with PBS. At 2 h, the coverslips were rinsed with PBS to remove free tachyzoites. After $24 \mathrm{~h}$ of incubation, the coverslips were rinsed three times with PBS and cells were collected and genome were obtained using a Genome DNA Extraction Kit (Sangon Biotech Co., China). Then the DNA was adjusted to $20 \mathrm{ng} / \mu \mathrm{l}$ and the parasite burden was determined by real-time fluorescent quantitative PCR. The Nc-5 sequence of $N$. caninum was detected using a BioEasy SYBR Green I Real Time PCR Kit (Roche, United States) following the manufacturer's instructions with the primer pairs (forward primer, 5'-TCCCTC GGTTCACCCGTTCACACAC-3', reverse primer, 5'-CACGTATCCCACCTC TCACCGCTACCA-3'). Cell GAPDH were used as the control and the relative numbers of $N$. caninum in cells were calculated by SPSS. In addition, some sets of monolayers were fixed with cold methyl alcohol and stained with acridine orange (Life Technologies, United States), which were observed using a FV1000 confocal microscopy (Olympus Co., Japan). The number of tachyzoites per 100 cells and the numbers of tachyzoites in vacuoles were determined by counting at $\times 1,000$ magnification. Experimental groups had triplicate samples and at least $100-200$ cells or 100 vacuoles per sample were counted.

\section{Statistical Analysis}

Results were obtained from triplicate values in each independent experiment and analyzed for statistical significance using Student's $t$-test and one-way ANOVA by SPSS 19.0 software. Results are expressed as the mean \pm standard errors. Differences were considered statistically significant when $p$-values were $<0.05\left({ }^{*} p<0.05\right.$ and ** $p<0.01)$.

\section{RESULTS}

\section{Neospora caninum Infection Induced EGFR-Like Activation in Tachyzoites}

To examine whether $N$. caninum could induce phosphorylation of EGFR on the cell surface, purified tachyzoites were inoculated to HEK-293 cells. Immunofluorescence staining with tyrosine residue 1068 specific phosphor antibody suggested that not only cell EGFR was phosphorylated; $N$. caninum infection also induced activation of EGFR-like on tachyzoites themselves (Figure 1). Phospho-EGFRspecific fluorescence could be observed as early as $10 \mathrm{~min}$ after infection, while phospho-EGFR (Tyr1068) expression could not be observed in tachyzoites which were not inoculated into cells, as shown in Figure 1. Thus, $N$. caninum infection caused rapid EGFR-like activation in tachyzoites. 


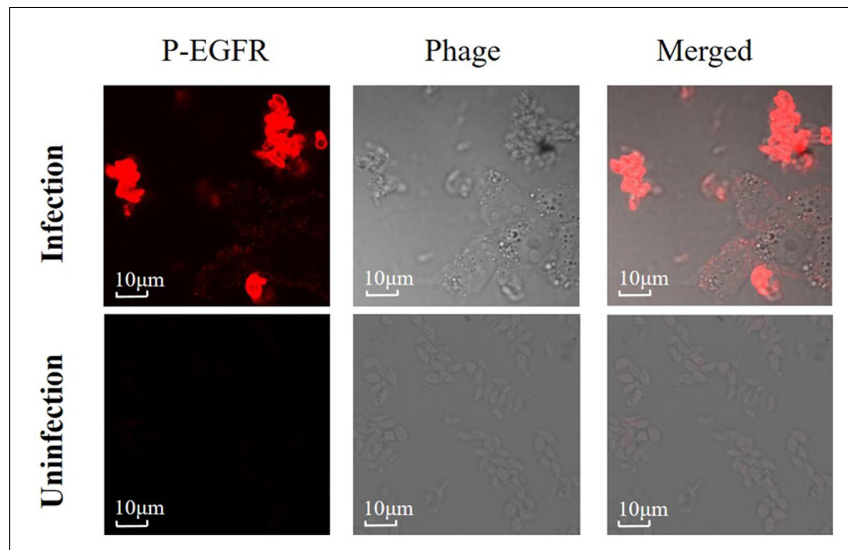

FIGURE 1 | Neospora caninum infection induces EGFR-like activation in tachyzoites. Purified N. caninum tachyzoites (Nc-1) were inoculated into HEK-293 cells or not at a MOI of 10, then phosphorylation of EGFR (Tyr1068) were detected at 10 min by immunofluorescence. Results are representative of three independent experiments.

\section{Identification of Putative EGFR-Like in N. caninum Tachyzoites}

In order to determine the expression of parasite EGFR, protein extracts from $N$. caninum tachyzoites and HEK293 cells were subject to immunoblot using mAb against EGFR and $\beta$-actin, respectively. An EGFR-specific protein band with a molecular weight of $170 \mathrm{kDa}$ was shown in both tachyzoite and HEK-293 cell lysates as shown in the left panel of Figure 2A. Moreover, the $\beta$-actin protein band $(45 \mathrm{kDa})$ was present in HEK-293 cell lysates while not in tachyzoite lysates, suggesting that tachyzoite extracts were not contaminated with cell proteins as shown in the right panel of Figure 2A. Meanwhile, the results from immunofluorescence staining using the antibody specifically against EGFR also suggested the expression of EGFR-like in $N$. caninum tachyzoites (Figure 2B). In addition, co-localization of the EGFR-like with SAG1 in $N$. caninum by IFA indicated that $N$. caninum EGFR-like located on the tachyzoite surfaces (Figure 2C).

\section{EGF-Induced PKC Activity in $\mathbf{N}$. caninum Tachyzoites}

Next, the ability of EGFs to induce PKC activities in tachyzoites was investigated. PKC activities in tachyzoites before or after stimulation with rNcMIC3 or hEGF were measured. The results showed that after treatment with the recombinant proteins, the PKC activities in tachyzoites were significantly increased in a concentration and time dependent manner. When incubated with rNcMIC3 (Figure 3A, $p<0.01$ ) at $100 \mathrm{ng} / \mathrm{ml}$ or hEGF (Figure 3B, $p<0.01$ ) at $50 \mathrm{ng} / \mathrm{ml}$ for $10 \mathrm{~min}$, the $\mathrm{PKC}$ activity peaked and increased by 50.7 and $48.8 \%$ compared to control, respectively, while these increases were both effectively inhibited when treatment with $20 \mu \mathrm{M}$ EGFR-inhibitor AG1478 (Figure 3C, $p<0.01$ ). The results suggested that the EGFdependent PKC activity was present in N. caninum tachyzoites.

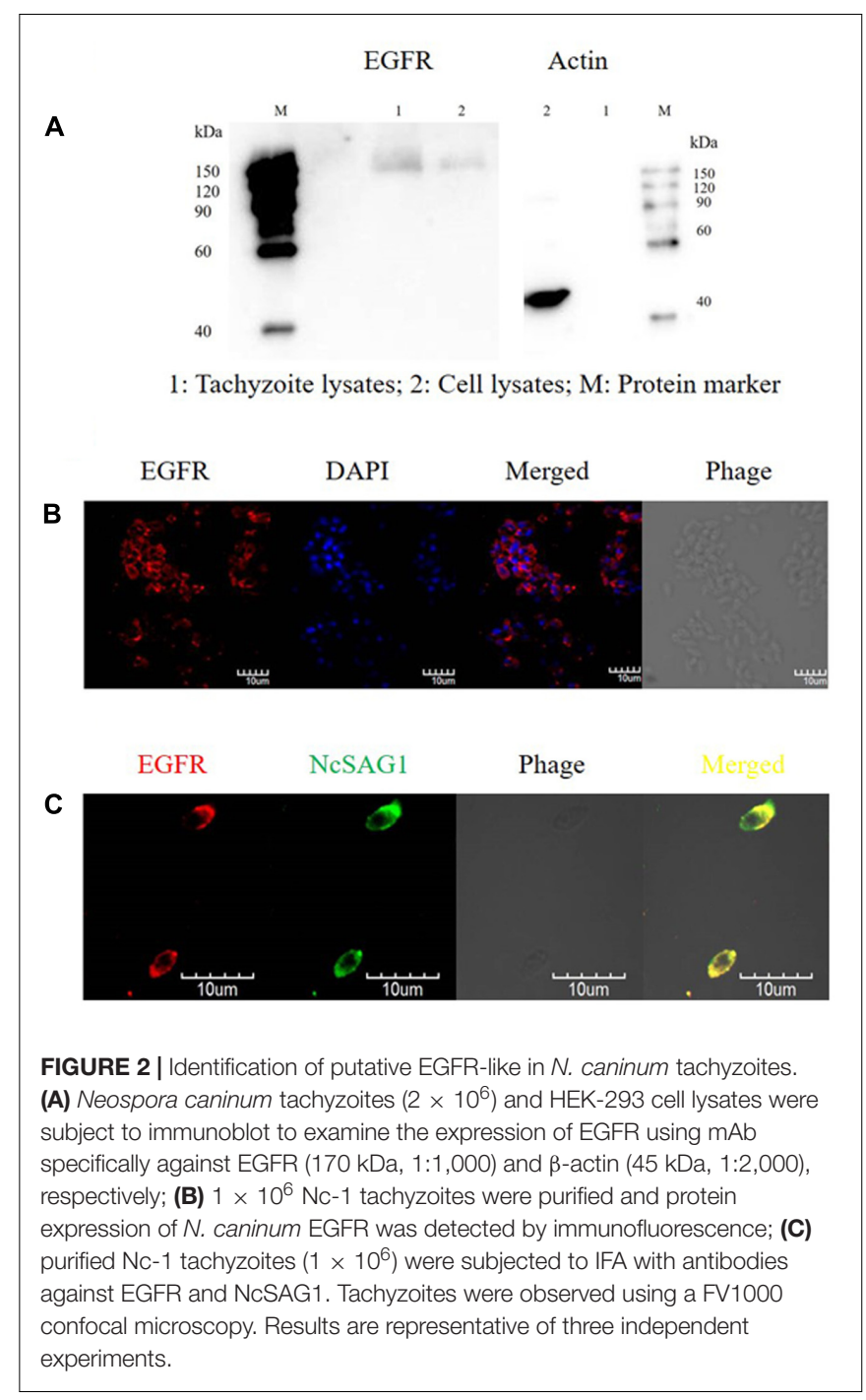

\section{RNcMIC3 and hEGF Induced the Activation of Tachyzoite EGFR-Like}

To examine whether $N$. caninum MIC3 which contains four EGF repeats and hEGF were involved in the activation of parasite EGFR-like, purified tachyzoites were treated with or without $\mathrm{rNcMIC3}$ or hEGF with or without the presence of AG1478. Immunoblot results suggested that phosphorylation of tachyzoites EGFR-like $(170 \mathrm{kDa})$ increased with recombinant hEGF and NcMIC3 in a doseand time-dependent manner, respectively, compared to control. EGFs-induced phosphorylation of parasite EGFRlike peaked at $50 \mathrm{ng} / \mathrm{ml}$ of hEGF (Figure $4 \mathrm{~A}, p<0.01$ ) or at $100 \mathrm{ng} / \mathrm{ml}$ of rNcMIC3 (Figure $4 \mathbf{B}, p<0.01$ ) both for $10 \mathrm{~min}$. Furthermore, results from co-incubation of $50 \mathrm{ng} / \mathrm{ml} \mathrm{hEGF}$ (Figure 4C, $p<0.05$ ) or $100 \mathrm{ng} / \mathrm{ml} \mathrm{rNcMIC3}$ (Figure 4D, $p<0.05$ ) with $20 \mu \mathrm{M}$ AG1478 for 10-60 min showed that the phosphorylation levels of tachyzoites EGFRlike induced by the recombinant proteins were significantly decreased at every time point. These results showed that 

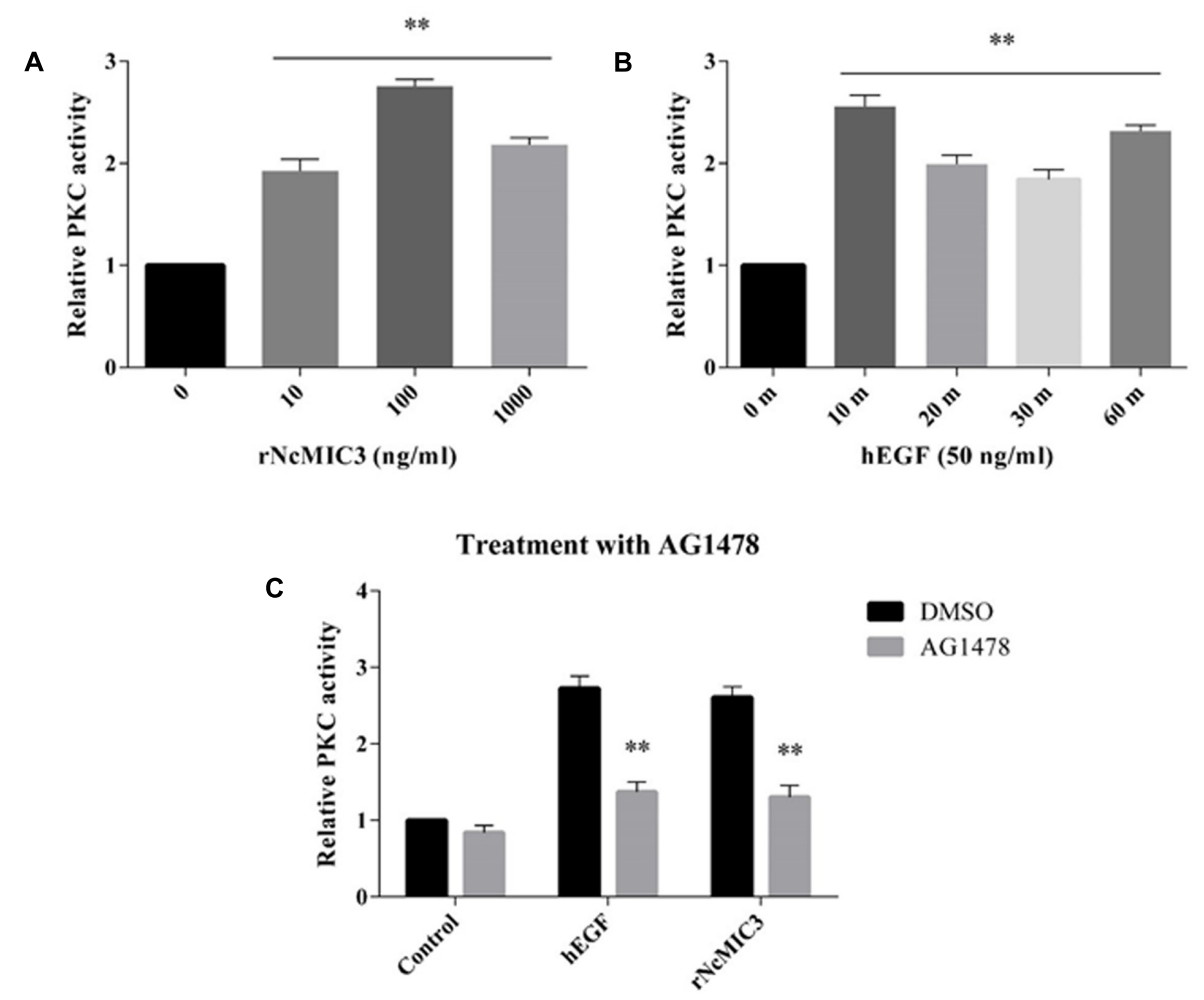

FIGURE 3 | EGF-induced PKC activity in N. caninum tachyzoites. (A) Nc-1 tachyzoites $\left(1 \times 10^{7}\right)$ were incubated with $0,10,100$, or $1,000 \mathrm{ng} / \mathrm{ml} \mathrm{rNcMIC3}$ at $37^{\circ} \mathrm{C}$ for $10 \mathrm{~min}$; (B) $1 \times 10^{7}$ tachyzoites were incubated with 0 or $50 \mathrm{ng} / \mathrm{ml} \mathrm{hEGF}$ for $10-60 \mathrm{~min}$ at $37^{\circ} \mathrm{C}$; (C) to test the inhibition effect by EGFR kinase inhibitor (AG1478), tachyzoites $\left(1 \times 10^{7}\right)$ were incubated with $20 \mu \mathrm{M}$ AG1478 or DMSO, then stimulated with $100 \mathrm{ng} / \mathrm{ml} \mathrm{rNcMIC3}$ or $50 \mathrm{ng} / \mathrm{ml} \mathrm{hEGF}$ for $10 \mathrm{~min}$ at $37^{\circ} \mathrm{C}$. Tachyzoite lysates were obtained for PKC activity measure by ELISA using a non-radioactive PKC assay kit. Samples were applied in triplicates. Results represent the mean of three independent experiments \pm SD. ${ }^{*} p<0.05 ;{ }^{* *} p<0.01$.

rNcMIC3 and hEGF promoted the activation of tachyzoite EGFR-like.

\section{Activated Tachyzoite EGFR-Like Promoted Intracellular N. caninum Proliferation}

Finally, we explored the role of tachyzoite EGFR-like activation in parasite proliferation in host cells. The results from acridine orange staining indicated that treatment or pretreatment with specific EGFR-inhibitor AG1478 $(20 \mu \mathrm{M}$, which was close to the highest IC50 and exhibited no toxicity to cells) obviously decreased the ability of the tachyzoites to grow within vacuoles in HEK-293 cells. AG1478 treatment decreased not only the number of tachyzoites per 100 cells by $52.9 \%$ (Figures $\mathbf{5 A , C}$, $p<0.01$ ), but also the number of tachyzoites per vacuole (Figures 5B,C, $p<0.01$ ) at 24 h. AG1478 pretreatment on tachyzoites only induced a small but significant reduction in the number of tachyzoites per 100 cells of $21.2 \%$ and per vacuole at $24 \mathrm{~h}$ (Figures $\mathbf{5 A - C}, p<0.05$ ). In addition, the results from real-time fluorescent quantitative PCR showed that treatment or pretreatment with AG1478 significantly reduced the parasite burden in HEK-293 cells by $42.3 \%(p<0.01)$ and $23.4 \%(p<0.05)$ at $24 \mathrm{~h}$, respectively (Figure 5D). These data suggested that inhibition of EGFR kinase activities both on parasites and hosts by AG1478 hindered the intracellular development of parasites, suggesting that tachyzoite EGFR-like might be involved in $N$. caninum proliferation within host cells.

\section{DISCUSSION}

EGFR is a receptor TK of $170 \mathrm{kDa}$ belonging to the HER/ErbB protein family. EGFR signaling pathway plays critical roles in numerous cellular physiological processes. EGFR has been identified and sequenced in many animal species (Yang et al., 2017). EGFR homologs have been identified in Drosophila, Caenorhabditis elegans, Schistosoma mansoni, and Trypanosoma brucei trypomastigotes, T. cruzi amastigotes and Echinococcus multilocularis (Ghansah et al., 2002; Spiliotis et al., 2003). This study was the first to identify a putative EGFR-like kinase on Apicomplexan protozoan through Western-blot analysis and immunofluorescence staining. Furthermore, co-localization with NcSAG1 confirmed that $N$. caninum EGFR-like distributed on the surfaces of tachyzoites.

In the present study, we discovered that EGFR-like tyrosine residue of tachyzoites phosphorylated during cell infection, 


\section{A}
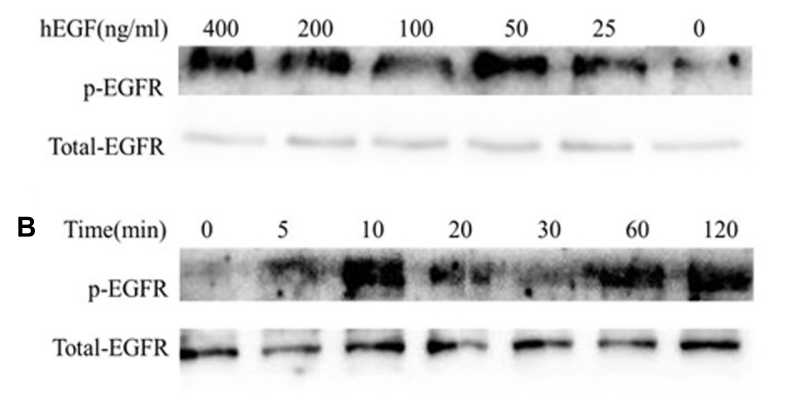

C

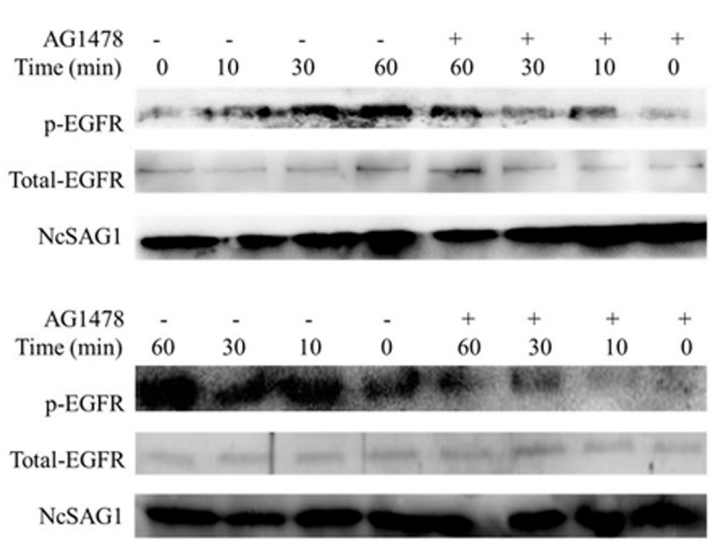

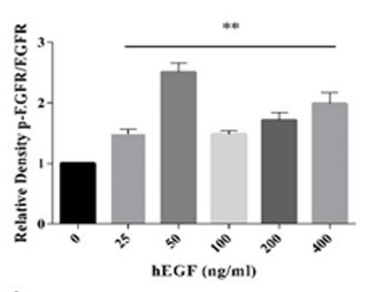
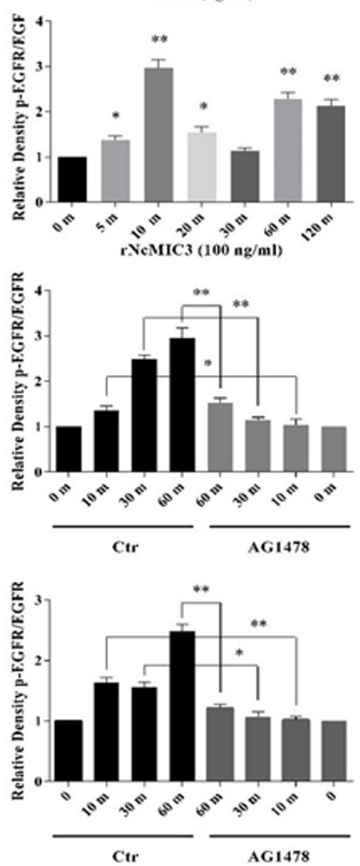

FIGURE 4 | rNcMIC3 and hEGF induce the activation of tachyzoite EGFR-like. (A) Nc-1 tachyzoites $\left(2 \times 10^{6}\right)$ were incubated with hEGF at different concentrations $\left(0-400 \mathrm{ng} / \mathrm{ml}\right.$ ) for $10 \mathrm{~min}$ at $37^{\circ} \mathrm{C}$; (B) $2 \times 10^{6}$ tachyzoites were incubated with 0 or $100 \mathrm{ng} / \mathrm{ml} \mathrm{rNcMIC} 3$ for $5-120 \mathrm{~min}$; (C) $2 \times 10^{6}$ tachyzoites were incubated with 0 or $50 \mathrm{ng} / \mathrm{ml}$ hEGF for 10, 30, and $60 \mathrm{~min}$ in the presence of AG1478 $(20 \mu \mathrm{M})$ or DMSO; (D) $2 \times 10^{6}$ tachyzoites were incubated with 0 or $100 \mathrm{ng} / \mathrm{ml} \mathrm{rNcMIC3}$ for 10,30 , and $60 \mathrm{~min}$ in the presence of AG1478 $(20 \mu \mathrm{M})$ or DMSO. After treatments, tachyzoite lyses were obtained for detection of phospho-EGFR (Tyr1068, $170 \mathrm{kDa}$ ) and EGFR (170 kDa) by western blot. NcSAG1 was used as the loading control. EGFR phosphorylation levels were calculated after normalization to the amount of total EGFR. Bars represent the mean \pm SD of three independent experiments. ${ }^{*} p<0.05 ;{ }^{* *} p<0.01$.

which could be inhibited by EGFR-inhibitor AG1478. Ligand binding to EGFR results in receptor dimerization, autophosphorylation, and activation of downstream signaling pathways. Activation of $N$. caninum EGFR might well be mediated by the binding of EGF domain containing ligand, such as host EGF or microneme proteins (MICs) that contain EGF domains. This binding induces receptor phosphorylation similar to those observed upon the binding of EGF to EGFR in mammalian cells. It has been shown that host EGF binds to EGFR on T. cruzi amastigotes induces the activation of protein kinases and signal transduction in amastigotes (Ghansah et al., 2002). Data from the present study suggested that both recombinant NcMIC3 and hEGF could induce the activation of parasite EGFR-like, which could be inhibited by AG1478. When exposed to rNcMIC3 or hEGF, $N$. caninum showed an EGF-dependent enhancement in PKC activity in tachyzoites in a dose- and time-dependent manners, which could also be inhibited by AG1478. These results indicated that EGFR-like TK might present in tachyzoites which could be activated by EGFs during cell invasion by the parasite.

Neospora caninum MICs contain EGF domains (MIC3, MIC6, and MIC8). NcMIC3 contains a lectin-like domain and four EGF repeats. NcMIC3 and TgMIC3 both have been demonstrated to be functionally involved in parasite infection (Naguleswaran et al., 2001; Meissner et al., 2002; Yang et al., 2015). It has been shown that N. caninum MIC3 is a secretory adhesin which interacts with Vero cell surface proteoglycan (Naguleswaran et al., 2002). T. gondii MIC3 binds to both the surface of the host cell and the surface of the parasite (Garcia-Réguet et al., 2000). Our results also suggested that $N$. caninum MIC3 might act on parasite EGFR-like. Additionally, tachyzoite EGFR-like might be involved in the interaction between parasites and hosts (Dissous et al., 2006).

Because of the roles of EGFR in cell growth and proliferation of mammalians, we propose the following possibility that EGFRlike in $N$. caninum would be likely to play some roles in parasite proliferation. It has been previously reported that 
A

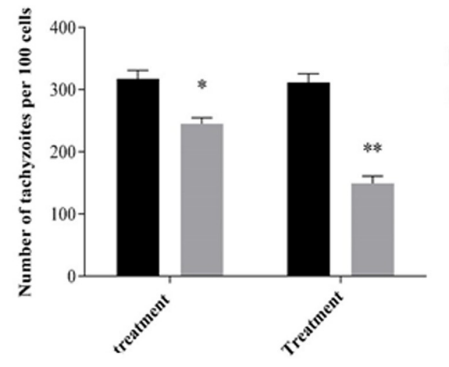

C

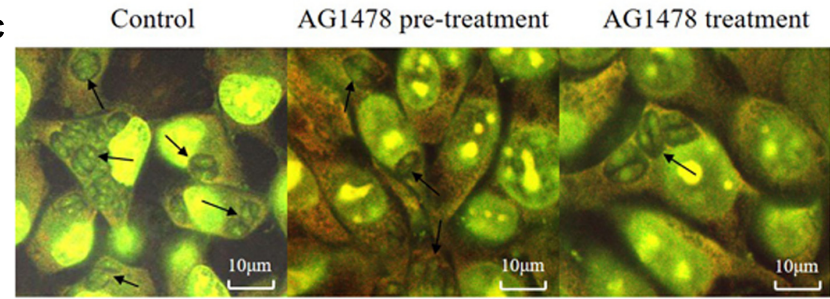

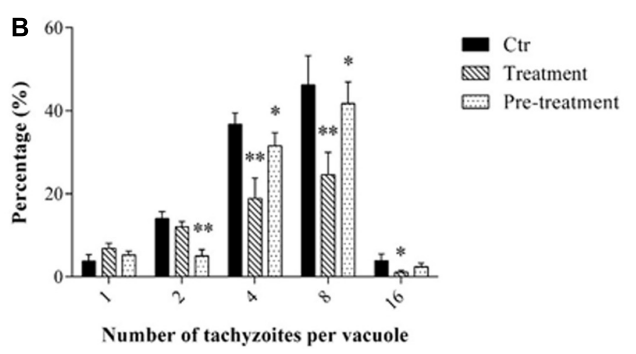

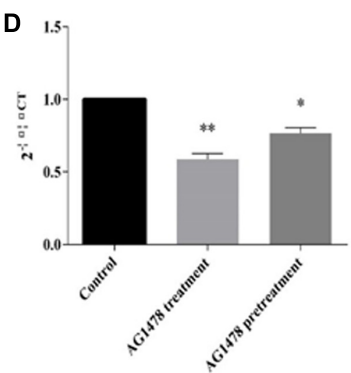

FIGURE 5 | Activated tachyzoite EGFR-like promotes N. caninum proliferation. For treatment, HEK-293 cells were inoculation with Nc-1 tachyzoites at a MOI of 10 in the presence of AG1478 (20 $\mu \mathrm{M})$ or DMSO (Ctr); for pretreatment, tachyzoites were pretreated with DMSO or AG1478 (20 $\mu$ M) for 2 h, followed by inoculating tachyzoites to HEK-293 cells after rinse with PBS. Parasite development in HEK-293 cells at 24 h were detected by acridine orange staining, which were observed using a FV1000 confocal microscopy. The number of tachyzoites/100 cells (A) and the numbers of tachyzoites in vacuoles (B) were determined by counting at $\times 1,000$ magnification. Experimental groups had triplicate samples and at least 100-200 cells or 100 vacuoles per sample were counted; (C) representative pictures from acridine orange staining; (D) HEK-293 cells were inoculated with tachyzoites at a MOI of 10 before (Ctr) or after treatment and pretreatment with AG1478 $(20 \mu \mathrm{M})$. N. caninum burden were detected by quantitative real-time PCR with Nc-5-specific sequence for $N$. caninum. The relative numbers of $N$. caninum were calculated by SPSS. Data are expressed as the mean of three independent experiments \pm SD. ${ }^{*} p<0.05 ;{ }^{* *} p<0.01$.

EGFR presents on T. cruzi amastigotes, which binds to host EGF to induce amastigote cell proliferation and the kinaseinhibitors AG1478 and PD89059 could inhibit the EGF-mediated growth of amastigotes (Ghansah et al., 2002). In the present study, we found that blockade of tachyzoite EGFR-TK activity by AG1478, which prevents ATP from binding to tyrosine residues of EGFR, inhibited both the number of intracellular tachyzoites and the numbers of tachyzoites per vacuoles at $24 \mathrm{~h}$ in HEK-293 cells by real-time fluorescent quantitative PCR and acridine orange staining, although parasite proliferation was partially restored when the inhibitor was removed, suggesting a reversibility of this inhibitor on parasite kinase homologs. After pretreatment of $N$. caninum with AG1478, parasite burden within cells and the number of tachyzoites per 100 cells reduced by 21.2 and $23.4 \%$, respectively. These data indicated that $N$. caninum EGFR-like had a significant role in parasite proliferation within host cells. It has been shown that drugs targeting EGFR-TK activity inhibit the intracellular development of Apicomplexa. Isoflavone analogs (dihydroxyisoflavone and trihydroxydeoxybenzoin derivatives) inhibit the proliferation of S. neurona, C. parvum, and N. caninum (Gargala et al., 2005). Gefitinib inhibits the growth of T. gondii in Hela cells (Yang et al., 2014). EGFR-TK might be targeted by parasite for intracellular proliferation, which therefore could be the potential target for chemotherapy.

The EGFR is a transmembrane TK. Parasite protein kinases have been suggested to play significant roles in the invasion, growth, and proliferation of parasites (Kim, 2004; Sibley, 2013). Serine protease inhibitors block invasion of host cells by Plasmodium falciparum (Conseil et al., 1999) and Toxoplasma (Alam, 2014). In Apicomplexan parasites, several kinases have been identified (Brumlik et al., 2011; Wei et al., 2013; Brown et al., 2014; Jin et al., 2017). In addition, the existence of parasite receptor kinase protein homologs similar to mammalian host cells implies that $N$. caninum EGFR might participate in host immune evasion by the parasite, which needs to be further studied.

\section{CONCLUSION}

We reported here for the first time that a putative EGFR-like kinase was present in $N$. caninum tachyzoites. N. caninum infection activated tachyzoite EGFR-like probably by NcMICs or host EGFs. Furthermore, a specific EGFR inhibitor (AG1478) effectively reduced EGF-dependent EGFR-like activation and PKC activity in tachyzoite and decreased parasite proliferation in host cells. Further studies will be needed to precisely identify the kinase sequences of parasite EGFR and its function during parasite infection. Results from present study will be helpful in better understanding of the complicated mechanism involved in parasite proliferation within host cells of Apicomplexan N. caninum. 


\section{AUTHOR CONTRIBUTIONS}

$\mathrm{XJ}, \mathrm{XZ}$, and JL conceived and designed the study. $\mathrm{XJ}$ and YY performed the experiments. XJ drafted the manuscript. PG analyzed the data. JL and GL critically revised the paper. All authors read and approved the final version of the manuscript.

\section{REFERENCES}

Alam, A. (2014). Serine proteases of malaria parasite Plasmodium falciparum: potential as antimalarial drug targets. Interdiscip. Perspect. Infect. Dis. 2014:453186. doi: 10.1155/2014/453186

Brown, K. M., Suvorova, E., Farrell, A., McLain, A., Dittmar, A., Wiley, G. B., et al. (2014). Forward genetic screening identifies a small molecule that blocks Toxoplasma gondii growth by inhibiting both host- and parasiteencoded kinases. PLOS Pathog. 10:e1004180. doi: 10.1371/journal.ppat. 1004180

Brumlik, M. J., Pandeswara, S., Ludwig, S. M., Murthy, K., and Curiel, T. J. (2011). Parasite mitogen-activated protein kinases as drug discovery targets to treat human protozoan pathogens. J. Signal Transduct. 2011:971968. doi: 10.1155/ 2011/971968

Conseil, V., Soête, M., and Dubremetz, J. F. (1999). Serine protease inhibitors block invasion of host cells by Toxoplasma gondii. Antimicrob. Agents Chemother. 43, 1358-1361.

Dissous, C., Khayath, N., Vicogne, J., and Capron, M. (2006). Growth factor receptors in helminth parasites: signalling and host-parasite relationships. FEBS Lett. 580, 2968-2975. doi: 10.1016/j.febslet.2006. 03.046

Dubey, J. P. (2003). Review of Neospora caninum and neosporosis in animals. Korean J. Parasitol. 41, 1-16. doi: 10.3347/kjp.2003.41.1.1

Dubey, J. P., Barr, B. C., Barta, J. R., Bjerkås, I., Björkman, C., Blagburn, B. L., et al. (2002). Redescription of Neospora caninum and its differentiation from related coccidia. Int. J. Parasitol. 32, 929-946. doi: 10.1016/S0020-7519(02)00094-2

Dubey, J. P., and Schares, G. (2011). Neosporosis in animals-the last five years. Vet. Parasitol. 180, 90-108. doi: 10.1016/j.vetpar.2011.05.031

Dubey, J. P., Schares, G., and Ortega-Mora, L. M. (2007). Epidemiology and control of neosporosis and Neospora caninum. Clin. Microbiol. Rev. 20, 323-367. doi: 10.1128/CMR.00031-06

Garcia-Réguet, N., Lebrun, M., Fourmaux, M. N., Mercereau-Puijalon, O., Mann, T., Beckers, C. J., et al. (2000). The microneme protein MIC3 of Toxoplasma gondii is a secretory adhesin that binds to both the surface of the host cells and the surface of the parasite. Cell Microbiol. 2, 353-364. doi: 10.1046/j.1462-5822.2000.00064.x

Gargala, G., Baishanbo, A., Favennec, L., Francois, A., BalletJ, J., and Rossignol, J. F. (2005). Rossignol inhibitory activities of epidermal growth factor receptor tyrosine kinase-targeted dihydroxyisoflavone and trihydroxydeoxybenzoin derivatives on Sarcocystis neurona, Neospora caninum, and Cryptosporidium parvum development. Antimicrob. Agents chemother. 49, 4628-4634. doi: 10.1128/AAC.49.11.4628-4634.2005

Ghansah, T. J., Ager, E. C., Freeman-Junior, P., Villalta, F., and Lima, M. F. (2002). Epidermal growth factor binds to a receptor on Trypanosoma cruzi amastigotes inducing signal transduction events and cell proliferation. J. Eukaryot. Microbiol. 49, 383-390. doi: 10.1111/j.1550-7408.2002.tb00216.x

Innes, E. A., Wright, S., Bartley, P., Maley, S., Macaldowie, C., Esteban, R. I., et al. (2005). The host-parasite relationship in bovine neosporosis. Vet. Immunol. Immunop. 108, 29-36. doi: 10.1016/j.vetimm.2005.07.004

\section{ACKNOWLEDGMENTS}

This work was supported by the National Basic Science Research Program (973 program) of China (Grant No. 2015CB150300), Changbai Mountain Scholars Program of Jilin Province and Department of Jilin Provincial Science and Technology of China (Grant No. 20130521005JH).

Jin, X., Gong, P., Li, G., Zhang, X., and Li, J. (2017). The p38 MAPK inhibitor, SB203580, inhibits cell invasion by Neospora caninum. Parasitol. Res. 116, 813-819. doi: 10.1007/s00436-016-5346-1

Kim, K. (2004). Role of proteases in host cell invasion by Toxoplasma gondii and other Apicomplexa. Acta Trop. 91, 69-81. doi: 10.1016/j.actatropica.2003.11.016

Meissner, M., Reiss, M., Viebig, N., Carruthers, V. B., Toursel, C., Tomavo, S., et al. (2002). A family of transmembrane microneme proteins of Toxoplasma gondii contain EGF-like domains and function as escorters. J. Cell Sci. 115, 563-574.

Naguleswaran, A., Cannas, A., Keller, N., Vonlaufena, N., Björkmanb, C., and Hemphilla, A. (2002). Vero cell surface proteoglycan interaction with the microneme protein NcMIC3 mediates adhesion of Neospora caninum tachyzoites to host cells unlike that in Toxoplasma gondii. Int. J. Parasitol. 32, 695-704. doi: 10.1016/S0020-7519(02)00014-0

Naguleswaran, A., Cannas, A., Keller, N., Vonlaufen, N., Schares, G., Conraths, F. J., et al. (2001). Neospora caninum microneme protein NcMIC3: secretion, subcellular localization and functional involvement in host cell interaction. Infect. Immun. 69, 6483-6494. doi: 10.1128/IAI.69.10.6483-6494.2001

Reichel, M. P., and Ellis, J. T. (2008). Re-evaluating the economics of neosporosis control. Vet. Parasitol. 156, 361-362. doi: 10.1016/j.vetpar.2008.06.002

Sibley, L. D. (2013). The roles of intramembrane proteases in protozoan parasites. Biochim. Biophys. Acta 1828, 2908-2915. doi: 10.1016/j.bbamem.2013.04.017

Spiliotis, M., Kroner, A., and Brehm, K. (2003). Identification, molecular characterization and expression of the gene encoding the epidermal growth factor receptor orthologue from the fox-tapeworm Echinococcus multilocularis. Gene 323, 57-65. doi: 10.1016/j.gene.2003.09.007

Wei, F., Wang, W., and Liu, Q. (2013). Protein kinases of Toxoplasma gondii: functions and drug targets. Parasitol. Res. 112, 2121-2129. doi: 10.1007/s00436013-3451-y

Yang, D., Liu, J., Hao, P., Wang, J., Lei, T., Shan, D., et al. (2015). MIC3, a novel cross-protective antigen expressed in Toxoplasma gondii and Neospora caninum. Parasitol. Res. 114, 3791-3799. doi: 10.1007/s00436-015-4609-6

Yang, Y. P., Ma, H., Starchenko, A., Huh, W. J., Li, W., Hickman, F. E., et al. (2017). A chimeric egfr protein reporter mouse reveals egfr localization and trafficking in vivo. Cell Rep. 19, 1257-1267. doi: 10.1016/j.celrep.2017.04.048

Yang, Z., Ahn, H. J., and Nam, H. W. (2014). Gefitinib inhibits the growth of Toxoplasma gondii in Hela cells. Korean J. Parasitol. 52, 439-441. doi: 10.3347/ kjp.2014.52.4.439

Conflict of Interest Statement: The authors declare that the research was conducted in the absence of any commercial or financial relationships that could be construed as a potential conflict of interest.

Copyright (c) $2017 \mathrm{Jin}, \mathrm{Li}$, Zhang, Gong, Yu and Li. This is an open-access article distributed under the terms of the Creative Commons Attribution License (CC BY). The use, distribution or reproduction in other forums is permitted, provided the original author(s) or licensor are credited and that the original publication in this journal is cited, in accordance with accepted academic practice. No use, distribution or reproduction is permitted which does not comply with these terms. 